\title{
Social work with children and families: Reflections of a critical practitioner
}

\author{
Steve Rogowski \\ Oxon, UK: Routledge. 2016. \\ ISBN 1472433718.pp.202. Hardback. NZD 150
}

$\mathrm{D}$ rawing on a long career as a frontline practitioner, Steve Rogowski has published a deeply theoretical reflection on social work with children and families. He is an exceptional commentator. Social Work with Children and Families is a radical, critical, and personal explanation of the demise of social work as a profession in the United Kingdom. Readers in Aotearoa New Zealand will find much of interest and many issues that resonate with their practice experience.

The author describes the 1950s-1970s as the golden days for the welfare state in the United Kingdom and, consequently, for social work there. Thatcherism led to neoliberalism and these movements replaced the social democratic consensus; and marketisation, privatisation, consumerisation, and managerialism became the new common sense. The real-life implications of these descriptors were that the state services were seen as inherently ineffective and inefficient, that a combination of state and community agencies were believed to promote choices for customers/ clients and that professional management was to be much preferred to practitioner leadership and control. In addition, there was a remoralisation whereby clients could again be held responsible for their choices and circumstances rather than being excused by social disadvantage. Class analysis and welfarism were replaced by individualism and self-responsibility, and effectively there was a shift from the nanny state to the muscular state.
The author describes social work with families in the United Kingdom as being limited to child protection. The intention now is to minimise risk, and this is not necessarily the same as making things better. Assessment tasks are the foremost activities in practice, and the predominance of electronic forms and frameworks has meant that practitioners are effectively e-technicians. Social workers also allocate, and ration, resources and signpost clients to community services that they once provided themselves. The majority of functions are proceduralised and management language is pervasive (e.g., investigation, problem families, welfare dependency). In the modernised work environment, interagency engagements, information sharing, and actuarial analysis (flagging up of identified families) are expected to effect a transformation despite the fact that these provisions are likely to have minimal impact on the daily experiences of practitioners or their clients. The steady deprofessionalisation of social work can be disorienting and dispiriting for practitioners, and it will most likely be disempowering and disabling for clients. Child protection is effectively a contemporary variant of child rescue, and the narrowness of its focus fails to accurately illuminate the familial, the societal, or the structural determinants of personal distress.

Social Work with Children and Families poses a central question for the human services of our age: is it possible to exercise professional agency within highly managerialist work settings? One possibility is that newer, and less well trained, social workers will become little more than a human face 
for bureaucracy. Another option is for practitioners to exploit the fact that social service organisations, however distrusting and disparaging, will continue to require social workers of sorts and these workers can subtly subvert systems by doing what is right for people rather than solely doing things right as the agency requires it. The author also sees hope in critical analysis and in an ethic of care. Rogowski admits that critical and postmodern perspectives do not readily translate into practical provisions but an ethic of care could do so as it contests the tenets of individualism, and it might replace these with new and perceptible expressions of responsiveness, responsibility, and competence. Nevertheless, it is unlikely that we will again see locality-based social workers who represented one of the high points of the profession's brief history in the United Kingdom. These practitioners had the understanding and the accessibility to provide proactive and preventive services, which assisted families to flourish, while being minimally intrusive and bureaucratic.

It is apparent that, like the clients it serves, social work in the United Kingdom has

Reviewed by Peter Stanley Tauranga, New Zealand been the casualty of pervasive political and economic forces. Unfortunately, it is doubtful if the present author is suggesting solutions of sufficient strength to regain the standing and influence of his profession. Rogowski's theoretical analysis is very informative and useful, but perhaps the future of social work now lies in dedicated and confident practitioners possessing demonstrable competencies and capabilities for casework and community development. The author can be dismissive of the authoritative caseworker and of evidence-based practices, but every occupation in the contemporary market place has to have something to sell; and to acknowledge this, and to take charge of it, is not the same as selling out. As we know, the faith of neoliberal politicians in the procedures and protocols of managerialism is misplaced because checklists and computers cannot stop families repeatedly coming to notice, and neither can they interrupt multiple generations of abuse and dependence. Only proven therapeutic skills and strategies can effect lasting change for individual families and for selected communities and, in doing what is right for them, social work might also be doing what is best for itself. 